\title{
Comprehensive Review of Growing Food Insecurity in Africa in Terms of Causes, Effects and Solutions: The Nigerian Example
}

\author{
Wasiu Olayinka Fawole*, Burhan Özkan \\ Department of Agricultural Economics, Faculty of Agriculture, Akdeniz University, 07070 Dumlupinar/Antalya, Turkey \\ A R T I C L E I N F \\ Research Article \\ Received 01 December 2016 \\ Accepted 23 January 2017 \\ Keywords: \\ Food Insecurity \\ People \\ Undernourishment \\ Africa \\ Nigeria \\ *Corresponding Author: \\ E-mail: wasiufawole@gmail.com \begin{abstract}
A B S T R A C T
This study examined the situation of food insecurity in Africa with special emphasis on Nigeria with a view to giving the picture of the trend with respect to causes, effects and possible solutions. The study employed secondary data sourced from the Food and Agricultural Organization (FAO) of the United Nations and subsequently compared the results with other previously conducted studies on food security status in Nigeria and few other African countries. Data for the trend of food security between 1990 and 2014 were sourced from FAO. The findings of this study combined with other previously conducted studies revealed that the food insecurity in Nigeria is not only becoming worrisome but frightening. According to the FAO three commonly employed indicators (prevalence of undernourishment, prevalence of food insecurity and number of undernourished people), it was observed that food insecurity in Nigeria continued to rise from 2009 according to the results of the annual survey till 2014. The implication of this is that if the trend is not halted as quickly as possible it is a time bomb that may pose grave security risks and danger to the country and Africa as a whole being the most populous black nation and it is almost certain that any destabilization suffered as a result of hunger in Nigeria is a destabilization of the entire sub-Saharan Africa region considering her enormous population and the strategic place she occupies in the economy of the region especially the western Africa. This paper made some far-reaching recommendations that could halt the trend if judiciously implemented.
\end{abstract}

DOI: https://doi.org/10.24925/turjaf.v5i6.629-636.1113

\section{Introduction}

Food security concerns as it is currently known dated back to the early 70s when it was first defined in the 1974 World Food Summit as "availability at all times of adequate world food supplies of basic foodstuffs to sustain a steady expansion of food consumption and to offset fluctuations in production and prices" (FAO, 1974). In 1983, FAO expanded its concept to include securing access by vulnerable people to available supplies, it was then defined as "ensuring that all people at all times have both physical and economic access to the basic food they need" (FAO, 1983). In 1986, the highly influential World Bank report "Poverty and Hunger" expanded the scope of food security further by taking into consideration the dynamism of food insecurity in terms of chronic and transitory food insecurity and redefined food security as "access of all people at all times to enough food for an active and healthy life (World Bank, 1986). By the mid1990 s, food security was recognized as a significant concern, the definition was reinvigorated to give more concern to the safety and the nutritional values of the food being consumed against the traditional focus on the availability of food in terms of quantity. Consequently, food security was redefined to include the nutritional values of foods being consumed. The World Food Summit of 1996 went further to define food security by segregating it into different levels as individual, household, national, regional and global levels. By categorization into these five levels, food security is perceived to have been achieved when "all people, at all times, have physical and economic access to sufficient, safe and nutritious food to meet their dietary needs and food preferences for an active and healthy life" (FAO, 1996).

Recently in 2001 shortly after the unveiling of millennium development goals (MDGs) that gave recognition to food security as global concerns, food security was redefined in the face of growing food insecurity in the world especially in developing countries as "a situation that exists when all people, at all times, have physical, social and economic access to sufficient, safe and nutritious food that meets their dietary needs and food preferences for an active and healthy life" (FAO, 2002). In this context, the new dimensions of dietary diversity and preferences were put into consideration as 
parts of the conditions necessary to attain a state of food security in such a way that the contents of foods being consumed in terms of the nutrients were put into consideration. It is worthy of note that this version of food security definition put into consideration the physical and economic access to safe, nutritious and sufficient food that meet the dietary and food preferences of the people to live active and healthy life. The National Food Security Programme (NSFP) on its own defined food security as the physical availability of food and ability of individuals to have access or afford same at reasonable costs (NFSP, 2001). On the other hand, United States Department for Agriculture (USDA), Bureau for Africa defined food security as a situation when all people at all times have access to sufficient food to meet their dietary needs for a productive and healthy life (USDA, 1997).

\section{Dimensions of Food Security}

According to FAO (2008), food security can be defined under four dimensions namely;

- Availability: This means availability of sufficient food through own production or other means that are sustainable for example in the case of a country that lacks the resources such as arable land for food cultivation,

- Accessibility: This means that the available foods are accessible by the households. In other words, the households or individual have both physical and economic access to the available foods in right quality and quantity,

- Utilization: This means ensuring good nutritional outcomes that can be termed nutrition security indicating there is sufficient personal hygiene for absorption of nutrients present in the food. Food utilization entails other factors such as personal hygiene and water sanitation,

- Sustainability: This is the last dimension of food security that is attained when the above three dimensions can be sustained in a stable manner over a period of time.

The above four dimensions of food security are independent of each other. This means that the achievement of one does not translate to the achievement of others and food security will not be said to have been attained unless the four dimensions are met. In summary, food availability does not guarantee accessibility the same way accessibility does not guarantee utilization just as all these three do not guarantee sustainability (Arene and Anyaeji, 2010).

\section{Importance of Food}

The earlier concerns about food availability have always been food policy that could enhance adequate availability of food for people at affordable price without taking into consideration the chemical composition in terms of adequate nutrients of food being consumed by the people. The latest concerns about food security as a concept started in the early 70 s as stated earlier. Okwoche and Benjamin (2012) in their study posited that food is widely accepted as a basic necessity of life because its importance at household level is obvious since it is a basic mean of sustenance. Helen (2002) in its own submission asserted that food is useful for maintaining political stability and ensuring peace among people while food insecurity can result to poor health and reduced performance in children. Shala and Stacey (2001) contended that many countries experience food insecurity with food supplies being inadequate to maintain their citizens' per capita consumption.

\section{Food Insecurity}

Food insecurity exists when people lack sustainable physical or economic access to enough, safe, nutritious, and socially acceptable food for a healthy and productive life. Food insecurity may be chronic, seasonal or transitory. Food insecurity and malnutrition result in substantial amount of human sufferings. According to Maharjan and Chhetri (2006), food insecurity is the inability of household or individual to meet the recommended minimum consumption threshold in the face of fluctuating production, price and income.

Food insecurity affects not only the human health and welfare but also contributes in parts to economic and political stability as it is often noticed that most countries of the world where there is political instability are always associated with food insecure territories, the food insecurity in such countries might have been as a result of political instability or the political instability was as a result of food insecurity just as the two are correlated. One often led to the other as they go hand in hand in the affected areas. The World Health Organization estimates that approximately 60 percent of all childhood deaths in the developing countries are associated with chronic hunger and malnutrition. Persistent malnutrition in these countries leaves children weak, vulnerable and less able to fight common childhood illnesses such as diarrhea, acute respiratory infections, malaria and measles. The United Nations estimates that about 805 million people approximately one in eight are undernourished as of 2014. The majority of these people live in developing countries where more than 14 percent of the people are unable to meet their dietary energy requirements.

According to Angela (2006), the root cause of food insecurity in developing countries is the inability of people to gain access to food due to poverty which literarily means lack of economic access according to FAO (2002) recognized definition of food security. While the rest of the world has made significant progress towards poverty alleviation, developing countries particularly in Sub-Sahara Africa continue to lag behind. Projections show that there will be an increase in this tendency unless preventive and proactive measures are taken. Food insecurity in the continent has worsened since 1970 and the proportion of the malnourished population has remained within the 33 to 35 percent range in SubSaharan Africa. The prevalence of malnutrition within the continent varies by region. It is lowest in Northern Africa with 4 percent and highest in Central Africa with 40 percent (FAO, 2014). 


\section{Categories of Food Insecurity}

There are three main categories of food insecurity as classified by the Food and Agricultural Organization (FAO) of the United Nations. The three categories are as follows;

- Acute: Severe hunger and malnutrition to the point that lives are threatened immediately (e.g. famine),

- Occasional: When food insecurity occurs due to a specific temporary circumstance (e.g. seasonality),

- Chronic: Ability to meet food needs is consistently or permanently under threat.

\section{Materials and Methods}

This study made use of Nigeria as a case study which is unarguably the most populous country in the African continent and the largest congregation of black race in the world. The population of Nigeria was put at 140 million in 2006 (NPC, 2006), estimated as 178.5 million in 2014 and 183.5 million in 2015 (Worldometers, 2015) with annual growth rate of $3.2 \%$ (Adesugba and Mavrotas, 2016).

The study used secondary data sourced from FAO statistics and previously conducted studies on food security were also reviewed to assess the rising food insecurity in Nigeria as depicted by various studies whose findings are highlighted subsequently. Data on key food security indicators by FAO such as prevalence of undernourishment, food insecurity and numbers of undernourished people in Nigeria from the year 1990 to 2014 were collected from FAO statistics and analyzed to give the appropriate inference as to the food insecurity in Nigeria which is of great concern to the stakeholders in food sub-sector in recent time.

Table 1 Nigerian Population Changes and growth rate between 2005 and 2015*

\begin{tabular}{l|cc}
\hline Year & $\begin{array}{c}\text { Population } \\
\text { (millions) }\end{array}$ & $\begin{array}{c}\text { Change yearly } \\
(\%)\end{array}$ \\
\hline 2015 & $183,523,432$ & 2.82 \\
2014 & $178,516,904$ & 2.82 \\
2010 & $159,707,780$ & 2.73 \\
2005 & $139,585,891$ & 2.58 \\
\hline
\end{tabular}

\section{Results and Discussions}

The results of the study are as presented on Table 2, the results show that as of the time of conducting this study, 805 million people corresponding to about one in nine of the world's population were chronically undernourished between 2012 and 2014, with insufficient food for an active and healthy life. This number represents a decline of more than 100 million people over the last decade and of 209 million since 1990 to 1992. The vast majority of hungry people live in developing regions, which saw 42 percent reduction in the prevalence of undernourished people between 1990 and 1992 and 2012 and 2014.
Despite this progress, about one in eight people or 13.5 percent of the overall population remain chronically undernourished in these regions, down from 23.4 percent between 1990 and 1992. Despite this, large differences remain across developing regions, for example Eastern and South-Eastern Asia have already achieved the MDGs hunger target. The same is true of Latin America and the Caribbean while the Caucasus and Central Asia were close to reaching MDGs first target by the end of 2015. Latin America and the Caribbean were also more ambitious to accomplish the hunger target of MDGs.

However, sub-Sahara Africa, Southern and Western Asia have registered insufficient progress in the accomplishment of MDGs hunger reduction target as demonstrated in the number of people with inadequate access to sufficient foods in right quality and amount. Sub-Sahara Africa has become home to more than a quarter of the world's undernourished people owing to an increase of 38 million in the number of hungry people since 1990 (FAO, 2014).

Furthermore, according to the FAO as highlighted on Table 3 subsequently, the prevalence of undernourishment, food insecurity and the number of undernourished people have been on increase in Nigeria since 2009 due to the enumerated causes as presented in subsequent sections. It is interesting to note that despite the current trend as shown in this paper, Nigeria still remains one of the few countries with lowest value in terms of prevalence of undernourishment, food insecurity and the number of undernourished people in the sub-Sahara Africa thus one of the most food secure countries in the region when compared with other countries in the region. This implied that much actions are still needed in the area of food security in the sub-Saharan Africa to ensure stability. However, the current trend whereby these indicators showed a rising food insecurity is not only worrisome but requires the immediate attention and subsequent actions of the concerned stakeholders in the food sub-sector through the suggested solutions as recommended subsequently by this paper.

Review of Previous Studies Conducted in African Countries on Food Security

In furtherance to the review of the current situation of food insecurity in Africa, this paper reviewed some similar studies that have been conducted on food security situation across African countries the findings of which are as presented in Table 4. The findings of Fakayode et al. (2009), Obayelu (2010) and Obayelu (2012) all conducted in Nigeria while Ndhleve et al. (2013) and Oni et al. (2013) conducted in South Africa among others as show on Table 4 also corroborated the position of FAO (2014) in its published state of food insecurity in the world that stated in unambiguous term the high prevalence of food insecurity in Nigeria and Africa as a whole. The aforementioned studies confirmed that the food insecurity is considerably high in the respective countries where the studies were conducted. 
Table 2 Distribution of hunger in the World: Number and Shares by Region $(1990-2014) *$

\begin{tabular}{l|cccc}
\multirow{2}{*}{\multicolumn{1}{c}{ Regions }} & \multicolumn{2}{c}{ Number (millions) } & \multicolumn{2}{c}{ Regional share (\%) } \\
\cline { 2 - 5 } & $1990-1992$ & $2012-2014$ & $1990-1992$ & $2012-2014$ \\
\hline Developed Regions & 20 & 15 & 2.0 & 1.8 \\
\hline Southern Asia & 292 & 276 & 28.8 & 34.3 \\
Sub-Saharan Africa & 176 & 214 & 17.3 & 26.6 \\
Eastern Asia & 295 & 161 & 29.1 & 20.0 \\
South Eastern Asia & 138 & 64 & 13.6 & 7.9 \\
Latin America \&Caribbean & 69 & 37 & 6.8 & 4.6 \\
Western Asia & 8 & 19 & 0.8 & 2.3 \\
Northern Africa & 6 & 6 & 0.6 & 1.6 \\
Caucasus \&Central Asia & 10 & 13 & 0.9 & 0.7 \\
Oceania & 1 & 805 & 0.1 & 0.2 \\
Total & 1015 & 100 & 100 \\
\hline
\end{tabular}

*Source: FAO, 2014.

Table 3 Distribution of prevalence of undernourishment, food security and number of undernourished people in Nigeria*

\begin{tabular}{l|cccc}
\hline \multicolumn{1}{c|}{ Indicators } & $2009-11$ & $2010-12$ & $2011-13$ & $2012-14$ \\
\hline Prevalence of Undernourishment (\%) & 5.5 & 5.7 & 6.0 & 6.4 \\
Prevalence of Food Insecurity (\%) & 9.7 & 9.9 & 10.4 & 11.0 \\
Number of Undernourished people (millions) & 8.9 & 9.4 & 10.2 & 11.2 \\
\hline *FAO 2014
\end{tabular}

*FAO, 2014

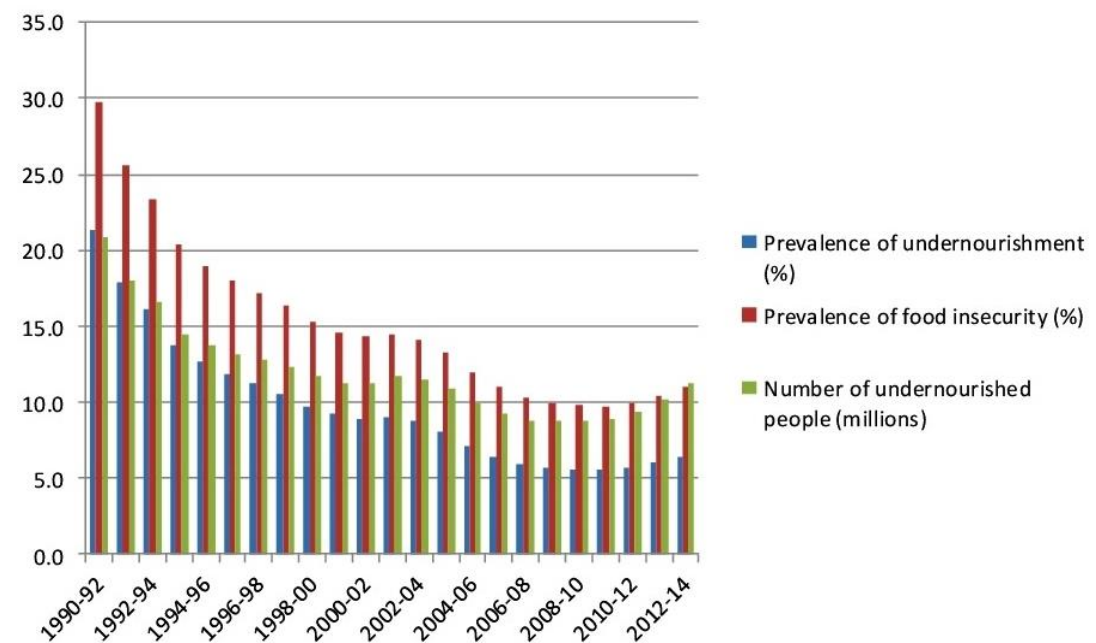

Figure 1 Prevalence of Undernourishment and food insecurity in Nigeria $(1990$ - 2014)

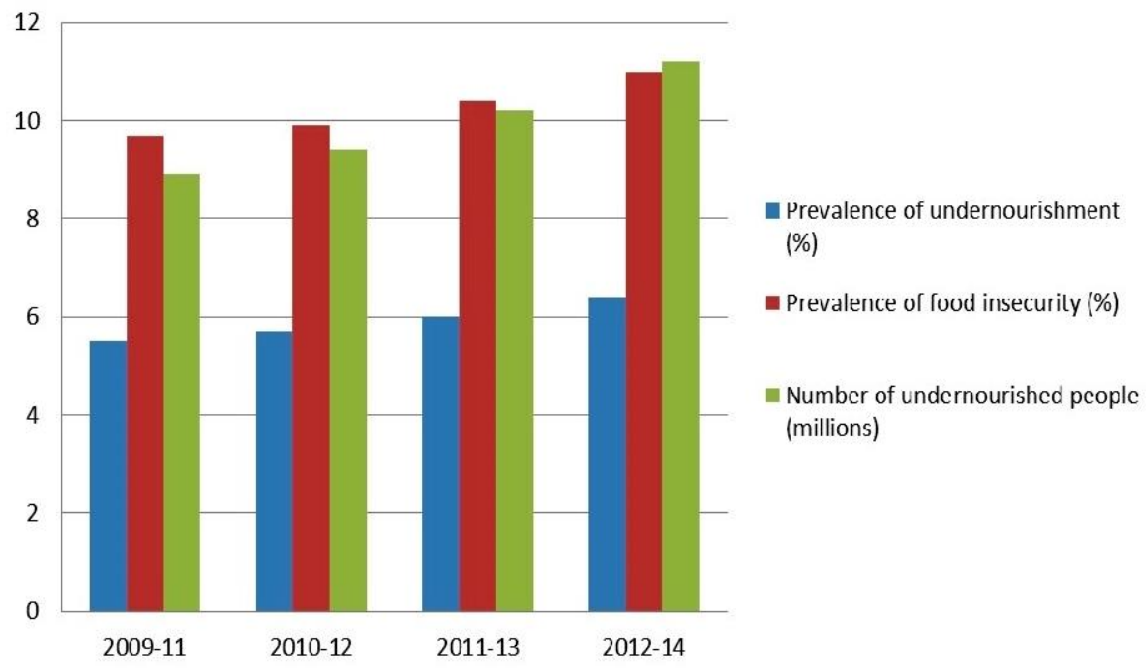

Figure 2 Prevalence of undernourishment, food insecurity and number of undernourished people in Nigeria (20092014) 
Table 4 Review of food security status in selected African countries in previous studies*

\begin{tabular}{l|ccc}
\multicolumn{1}{c|}{ Author } & Food Secure (\%) & Food Insecure (\%) & Location \\
\hline Amaza, et al. 2008 & 42 & 58 & Nigeria \\
Babatunde, et al. 2007 & 37.2 & 62.8 & Nigeria \\
De Cock, et al. 2013 & 47 & 53 & South Africa \\
Fakayode, et al. 2009 & 12.2 & 87.8 & Nigeria \\
Gebre, 2012 & 41.84 & 58.16 & Ethiopia \\
Irohibe and Agwu, 2014 & 74 & 26 & Nigeria \\
Kuwenyi et al. 2014 & 48.3 & 51.7 & Swaziland \\
Muche, et al. 2014 & 42.9 & 57.1 & Ethiopia \\
Omotesho and Muhammad-Lawal, 2013 & 34.55 & 65.45 & Nigeria \\
Ndhleve, et al. 2013 & 13 & 87 & South Africa \\
Obayelu, 2010 & 23.7 & 76.3 & Nigeria \\
Obayelu, 2012 & 16 & 84 & Nigeria \\
Omotesho, et al. 2006 & 34.16 & 65.86 & Nigeria \\
Oni, et al. 2013 & 12 & 88 & South Africa \\
Oyebanjo, et al. 2013 & 59.2 & 40.8 & Nigeria \\
Sanusi, et al. 2006 & 30 & 70 & Nigeria \\
\hline
\end{tabular}

*Source: Adapted from various studies that have been conducted on food security status

From the findings as shown on Table 4, it can be deduced that even where the findings showed some level of food security, it is still not a good proportion for food secure to food insecure households as in the case of Oyebanjo et al. (2013) which reported $59.2 \%$ food security and $40.8 \%$ food insecurity the ratio that can still be regarded as dangerous perhaps for the findings of Irohibe and Agwu (2014) which reported $74 \%$ food security and $26 \%$ food insecurity which is ordinarily not unexpected considering the location of the study which is understandably one of the agricultural zones in the country renowned for huge food production and semideveloped irrigation system coupled with the cosmopolitan nature of the study area which offers some degree of opportunities for inhabitants.

\section{Causes of Food Insecurity in Nigeria and African Countries}

There are many causes of food insecurity in Africa but the scope of this study is limited to that of Nigeria as presented earlier where it was revealed that the food insecurity is on the rise since 2009 in the country which gave a template to what is obtainable in other African countries due to the fact that countries in Africa face similar challenges as far as food insecurity and other development challenges are concerned but only differ in magnitude. Some of the popular and common causes of food insecurity are highlighted as follows;

War and Political Instability: The greatest threat to food security in Nigeria in recent years has come from the insurgency which has not only displaced millions of people but have destroyed the source of livelihoods particularly agriculture. The insurgency in north-eastern Nigeria has left about 2.1 million people displaced with many agricultural livelihoods destroyed thereby resulting in high prices where foods are available but not affordable to people (FAO, 2017). Like other countries of the world facing the problem of terrorism, Nigeria is passing through one of her greatest security challenges since independence from Britain in 1960.
Of the six geo-political zones in Nigeria, the northeast which is one of the critical zones that do not only provide the staple foods like grains, wheat and other staple foods but equally responsible for the supply of greater percentage of animal protein in form of meat is currently under siege by insurgents. This has continuously disrupted the agricultural activities in the area while businesses worth millions of Naira have equally been halted. Consequently, the food security of the area is not only affected but almost every part of the country that depended on them for year-round food supply thus resulting to hikes in the prices of food commodities in Nigeria.

Urbanization: Like other countries of the world, increasing rural-urban migration due to urbanization plays negative roles in the emerging food insecurity in Nigeria and other parts of the world. This has put unnecessary pressures on the cultivable land in the urban centers resulting to conversion of hitherto farm lands into residential areas thus reducing farming activities in most cases. This is currently happening in Nigeria already just like other countries in Africa which has hampered agricultural production in many facets. According to FAO (2014), 70 percent of the world population is expected to be living in cities by year 2050. By this, the agricultural production will be disrupted thereby increasing the food insecurity because of the projected pressures on land, water and other valuable resources necessary for agricultural productions.

Population growth: This is another factor similar to rural-urban migration mentioned earlier that is contributing to food insecurity in Nigeria. Currently, Nigeria is the sixth populous country in the world with the estimated population of about 183 million and annual growth rate of approximately 3.2 percent (Adesugba and Mavrotas, 2016). This has increased the demand for food products just like other countries without commensurable increase in food production to match because Nigerian agriculture growth rate stands at 2.7 percent or less (Fawole et al., 2016). According to the United Nations, 
Nigeria is expected to become third most populous country in the world by 2050 thus overtaking the United States of America considering her current growth rate (The Guardian, 13 June 2013). Cargill (2014) contended that feeding this growing global population in the years to come will require production of more food and distribution of the same in a manner that reaches more people which obviously not being met in most of the developing countries.

Poor agricultural sector development: This is another problem that poses grave threat to food security in Nigeria and Africa as whole. Most African countries including Nigeria do not have sustainable agricultural policy that can enhance food production and by extension food security in the long run. This is so because in Nigeria and across other African countries until recently did not have stable leadership structure due to prolonged military rule thereby resulting in policy somersault. Nigeria for example has not been on stable political leadership until 1999 when the country returned to full democracy devoid of military interruptions. The coherent policies in terms of formulation and implementation would have placed the country on a stable track that would have ensured that there is uninterrupted food supply backed by wellstructured value chain offered by a developed agricultural sector.

However, the situation has always been contrary just as successive governments have engaged in different agricultural policies that have led to cancellation of the existing ones even when they have proven prosperous and sustainable. Some government policies interfere with markets, create standards that inhibit trade and exposed the farmers to price shocks and risks.

Some of the government policies have not protected local farmers due to free importation of foods that are either produced or could be produced locally thereby exposing the farmers to avoidable risks coupled with fact that majority of farmers in Nigeria have been operating on subsistence scales and crude methods of production with low efficiency in most cases (Fawole and Rahji, 2016). Export restrictions and trading bans isolate local markets and give farmers little incentive to expand production for the next season thereby limiting the potential supply response to soaring prices.

Climate change: Climate change is another emerging threat to food security in the world and Africa in particular from which Nigeria is having her own unpalatable share of the menace created by climate change occasioned by earth warming. It has changed the productivity pattern in terms of depletion of mineral nutrients needed for sustainable food production as a result of increased temperature. The raining period which guarantee water for agriculture in Nigeria is less predictable now unlike what was obtainable before. The excessive heat created by climate change scares has deteriorated agricultural production because Nigeria is understandably operation a rain-fed agriculture due to low irrigation sector development.

\section{Effects Of Food Insecurity on Human Living}

Malnutrition: In developing countries, persistent food insecurity results to malnutrition which in turn has devastating effects on the population. It leaves the children weak and vulnerable by making their immune system unable to fight common childhood illnesses such as diarrhea, acute respiratory infections, malaria and measles that ordinarily foods in form of balanced diet with right composition of micronutrients would have nipped in the bud. Adolescents and adults also suffer adverse consequences of malnutrition caused by food insecurity. Malnutrition can lead to decreased energy levels, delayed maturation and growth failure, impaired cognitive ability, diminished learning capacity, decreased immunity, shortened life expectancy, increased maternal mortality and low birth weight.

Social instability: Food insecurity may also result to social instability and disorderliness instigated by social unrest just as food-insecure individuals may manifest feelings of alienation, powerlessness, stress, anxiety, reduced productivity, reduced work, reduced school performance and reduced income earnings as a result of which they may become agitated thereby resulting to national security threats. Household dynamics may become disrupted because of preoccupation with the stress of obtaining food which may lead to anger, pessimism and irritation among other vices among the members of the households.

\section{Recommended Solutions to the Problems of Food} Insecurity in Nigeria

Researchers and other stakeholders have consistently worked on the way forward for the lingering food crisis in Africa sub-region and Nigeria in particular. In order to mitigate the effects of food insecurity on the people there should be proactive actions on the side of the leaders and stakeholders in food sub-sector with a view to protecting people from starving to death as we are currently witnessing in some African countries which may snowball into Nigeria if early and adequate measures as recommended by this paper are not put in place before the situation escalates. To achieve this among other things, this paper suggests the subsequently listed course of actions among others with a view to reducing the incidence of food insecurity in Nigeria and by extension could be adapted to other African countries taking into consideration the peculiarities of the affected countries as follows;

Consistent policy framework: First and foremost, the leaders must adhere strictly to unique and sustainable agricultural policy developed by taking into account the peculiarity of the country and such policies will be subjected to periodic review by experts concerned to ensure all extant food policies conform with the international best practices as far as food security is concerned and the realities on ground instead of the continuous policy somersault we currently witness whereby every successive government comes with entirely different food and agricultural policies even when the existing ones are functional and sustainable. Once this 
is achieved, the successive governments will be able to pursue the food security with the desired vigour and pragmatism by designing the path through which the agricultural production will be revamped and food security restored to vulnerable households.

Infrastructural development: Provision of critical infrastructures such as roads, portable water, schools, hospitals, electricity and others are directly interwoven with food production through agricultural development. This should be made priority especially in the rural areas in order to prevent or reduce rural-urban migration which has constituted a major setback to the agricultural development in developing countries. Once this is achieved, it will ensure there is adequate labour for agricultural activities in the rural areas thereby increasing food production that will not only guarantee food security but will equally provide employment opportunities to the growing population particularly to the teeming youths in a way that will reduce the pressure on the urban centers and its infrastructures.

As a follow up to the above, government at all levels should encourage mechanized farming as a way of reducing the incidence of food insecurity by providing necessary infrastructures especially the irrigation that will ensure year-round food production. Currently, all over the world, agriculture is a serious business enterprise that has transformed beyond the subsistence farming whereby agriculture was seen as feeding tool for immediate family with little or nothing for income drive. Modern agriculture is not only concerned about feeding the household but in generating millions of employment and veritable source of income to both the farmers and the agricultural nations in form of foreign exchange earnings.

Population control: Just like other African countries where poverty is rampant, population is majorly uncontrolled as the methods of achieving this menace such as family planning and contraceptives are still unpopular especially in the rural areas where majority of the people and by extension the farmers in the developing countries including Nigeria reside thereby resulting to population surge among the people thus encouraging undue competition for limited resources including food. Government and other development partners such as World Bank, UNICEF, FAO, WFP and others should rise up to assist the government in educating people on birth control so that there can be assurance of food security at all levels. Campaigns for population control must be embarked upon to make people understand the need to abandon some social and religious considerations that encouraged unplanned family set up.

Provision of storage facilities: In addition to providing critical infrastructures for increased production, efforts should also be made to provide storage infrastructures in order to avoid waste that usually accompany harvest season in Nigeria. To achieve this, government and other stakeholders should do everything possible to ensure there is adequate processing and storage facilities for agricultural products so that there will be all year-round food security and in turn boost the income level of farmers who lose larger parts of their produce after harvest due to dearth of storage facilities consequently reducing poverty which is the ultimate goal of any government in the world. The current situation in Nigerian has become so worrisome that vast majority of the harvested crops waste away during the farming season while huge amount of money is being used by the government to offset the import bills of the same commodities during the off season which consequently depletes the foreign reserves.

Abolition of trade barriers: To avoid the trade restrictions among most African countries, free trade across African borders should be encouraged while the existing ones should be enforced to guarantee free flow of food and other commodities across borders. Though, there are various extant trade agreements with other African countries especially the west Africa but the enforcement across member nations has been very weak and sometimes non-existing. If these trade agreements are fully operational the food insecurity will not only be minimized in Nigeria but in other African countries and will lead to more income accruable to the farmers who produce these foods in various countries.

\section{Conclusion}

Based on the major findings as presented earlier, this paper has been able to establish the general concerns that are being expressed lately by stakeholders in the food sub-sector in Nigeria as regards the rising food insecurity by putting it into perspectives and simple concepts that could be well understood not only by experts but by those non-experts who have vital roles to play in ensuring food security in Nigeria. This study has not only established the incidence of food insecurity in Nigeria but has equally affirmed its rising.

Apart from the results of the analysis of the data obtained from the FAO statistics and publications which employed the indicators such as number of undernourished people, prevalence of undernourishment and prevalence of food insecurity to confirm the rising incidence of food insecurity in Nigeria, the previously conducted similar studies in few selected African countries such as South Africa, Swaziland and Ethiopia have also corroborated the rising food insecurity in Africa as a continent the same way some findings of previous works corroborated the incidence of rising food insecurity in Nigeria just as most of them affirmed that majority of the households whose food security status were investigated are food insecure meaning that they lack adequate, sufficient and sustainable access to enough, safe, nutritious, acceptable and preferred foods that can enable them maintain a healthy and active life as envisaged by the United nations.

\section{References}

Adesugba M, Mavrotas G. 2016. Delving Deeper into the Agricultural Transformation and Youth Employment Nexus: The Nigerian case, International Food Policy Research Institute (IFPRI) and Nigeria Strategy Support Program (NSSP) Working Paper No. 31, March 2016 
Amaza PS, Adejobi AO, Fregene, T. 2008. Measurement and determinants of food insecurity in North East Nigeria: Some Empirical Policy Guidelines. Journal of food, Agriculture and Environment. 6 (2): 92-96.

Angela M. 2006. Achieving Food Security in Africa: The Challenges and Issue. Available at: http://www.foodsecurity.nl/resource/achieving-food-security-africa-challengesand-issues

Arene, CJ, Anyaeji, RC. 2010. Determinants of Food Security among Households in Nsukka Metropolis of Enugu State of Nigeria, Pakistan Journal of Social Sciences (PJSS), Vol. 30 No. 1, pp. 9-16.

Babatunde, RO, Omotesho, OA, Sholatan, OS. 2007. Socioeconomics characteristics and food security status of farming households in Kwara State, North Central Nigeria”, Pakistan Journal of Nutrition, Vol. 6 No. 1, pp. 49-58

Cargill. 2014. Food Security - The Challenges, available online at: http://www.cargill.com/wcm/groups/public/@ ccom/documents/ document/na3059573.pdf

De Cock N, D’Haese M, Vink N, Van Rooyen CJ, Staelens L, Schönfeldt HC, D'Haese L. 2013. Food security in rural areas of Limpopo province, South Africa. Journal of Food Security No. 5, 269-282.

Fakayode SB, Rahji MAY, Oni OA, Adeyemi MO. 2009. An assessment of Food Security Situations of Farm Households in Nigeria: A USDA Approach. The Social Sciences, 4(1): 24-29.

FAO. 1974. World Food Summit, 1974, Rome, Italy.

FAO. 1983. World food security: A reappraisal of the concepts and approaches, Director General's report, FAO, Rome, available at: www.fao.org

FAO. 1996. World Food Summit 1996, Rome, Italy, available online at: www.fao.org

FAO. 2002. The State of Food Insecurity in the World 2001, Rome, available online at: www.fao.org

FAO. 2005. Assessment of the world food security situation; Committee on World Food Security, 31st session, May 23-26, available at www.fao.org.

FAO. 2008. An introduction to basic concepts of food security, ECFAO Food security Programme, available at: http://www.foodsec.org/docs/concepts_guide.pdf

FAO. 2014. The State of Food Insecurity in the World, SOFI, 2014, available online at http://www.fao.org/publications/ sofi/2014/en/

FAO. 2017. Global report on food crises 2017, available online at: http://www.fao.org/3/a-br323e.pdf

and http://www.fao.org/emergencies/resources/documents/resources -detail/en/c/876564/

Fawole WO, Rahji MAY. 2016. Determinants of Productivity among Farmers in Ondo State of Nigeria, Asian Journal of Agricultural Extension, Economics \& Sociology, Vol. 9 No. 4, pp. 1-7.

Fawole WO, Ozkan B, Ayanrinde, FA. 2016. Measuring food security status among households in Osun State, Nigeria. British Food Journal, 118 (7): 1554 - 1567.

Gebre GG. 2012. Determinants of food insecurity among Households in Addis Ababa city, Ethiopia. Interdisciplinary Description of Complex Systems, 10(2): 159-173.

Helen HJ. 2002. Food Insecurity and the food stamp Programme. American Journal of Agricultural Economics, 84 (5): 1215 1218.

Irohibe IJ, Agwu AE. 2014. Assessment of Food Security Situation among Farming Households in Rural Areas of Kano State, Nigeria. Journal of Central European Agriculture, 15(1): 94107.

Kuwenyi S, Kabuya, FI, Masuku, MB. 2014. Determinants of Rural Households' Food Security in Shiselweni Region, Swaziland: Implications for Agricultural Policy", IOSR Journal of Agriculture and Veterinary Science (IOSR-JAVS). 7 (11): 4450.
Maharjan KL, Chhetri AK. 2006. Household Food Security in Rural Areas of Nepal, Relationship between socioeconomic characteristics and food security status. Paper Presented at the International Association of Agricultural Economists' Conference, Gold Coast, Australia, August 12-26, 2006.

Muche M, Endalew B, Koricho T. 2014. Determinants of Household Food Security among Southwest Ethiopia Rural Households. Food Science and Technology, 2(7): 93-100.

National Food Security Programme, 2001. Easy Route to Food Availability, available online at: www.fao.org.

National Population Commission, 2006. Nigerian Population Census, 2006 Populations Census Results for Oyo and Osun States, National Population Commission, Abuja

Ndhleve S, Musemwa L, Zhou L. 2013. Household food security in a coastal rural community of South Africa: Status, causes and coping strategies. African Journal of Agriculture and Food Security, 1 (1): 15-20.

Obayelu AE. 2010. Classification of Households into Food Security Status in the North-Central Nigeria: An Application of Rasch Measurement Model. ARPN Journal of Agricultural and Biological Science, 5 (3): 26-41.

Obayelu AE. 2012. Households' food security status and its determinants in the North-Central Nigeria, Food Economics. Journal of Food Economics, 9 (4): 241-256.

Okwoche VA, Benjamin CA. 2012. Analysis of food security situation among Nigerian rural farmers, International Journal of Biological, biomolecular, agricultural, food and biotechnological engineering, 6 (12): 1-5.

Omotesho OA, Muhammad-Lawal A. 2013. Optimal food plan for rural households' food security in Kwara State, Nigeria: The goal programming approach. African Journal of Agriculture and Food Security, 1 (4): 75-81.

Omotesho O A, Adewumi MO, Muhammad-Lawal A, Ayinde OE. 2006. Determinants of Food Security among the Rural Farming Households in Kwara State, Nigeria. African Journal of General Agriculture. 2(1).

Oni SA, Maliwichi LL, Obadire OS. 2013. Socio-economic factors affecting smallholder farming and household food security: A case of Thulamela local municipality in Vhembe District of Limpopo Province, South Africa. African Journal of Agriculture and Food Security, 1 (5): 93-99.

Oyebanjo O, Ambali OI, Akerele EO. 2013. Determinants of food security status and incidence of food insecurity among rural farming households in Ijebu Division of Ogun State, Nigeria. Journal of Agricultural Science and Environment, No13, 92103.

Sanusi RA, Badejo CA, Yusuf BO. 2006. Measuring Household Food Insecurity in Selected Local Government Areas of Lagos and Ibadan, Nigeria. Pakistan Journal of Nutrition,5 (1): 62-67.

Shala A, Stacey E. 2001. Food Security Assessment, Regional Overview Information Bulletin. United States Department of Agriculture: Economic Research Service, 2001.

The Guardian, UK. 2013. Nigerian Population to Overtake US by 2030, available online at: http://www.theguardian.com/globaldevelopment/2013/jun/13/nigeria-larger-population-us-2050. 13 June 2013.

United States Department for Agriculture, 1997. Food Security Assessment, Economic Research Services, United States Department of Agriculture, Washington, D. C

World Bank, 1986. Poverty and Hunger, Issues and Options for Food Security in Developing Countries, Washington DC

Worldometers. 2015. Distribution of World Population by countries. available online at: http://www.worldometers.info/worldpopulation/nigeria-population/. 